\title{
Assessing the Impacts of the 2009/2010 Drought on Vegetation Indices, Normalized Difference Water Index, and Land Surface Temperature in Southwestern China
}

\author{
Xiaoqiang Zhang, ${ }^{1,2}$ Yasushi Yamaguchi, ${ }^{1}$ Fei Li, ${ }^{2}$ Bin $\mathrm{He}^{2}$ and Yaning Chen ${ }^{3}$ \\ ${ }^{1}$ Department of Earth and Environmental Sciences, Graduate School of Environmental Studies, Nagoya University, D2-1(510), \\ Furo-cho, Chikusa-ku, Nagoya 464-8601, Japan \\ ${ }^{2}$ Key Laboratory of Watershed Geographic Sciences, Nanjing Institute of Geography and Limnology, Chinese Academy of Sciences, \\ 73 East Beijing Road, Nanjing 210008, China \\ ${ }^{3}$ State Key Laboratory of Desert and Oasis Ecology, Xinjiang Institute of Ecology and Geography, Chinese Academy of Sciences, \\ No. 818 South Beijing Road, Urumqi, Xinjiang 830011, China \\ Correspondence should be addressed to Xiaoqiang Zhang; dr.xqzhang@gmail.com, \\ Fei Li; fli@niglas.ac.cn, and Bin He; hyhebin@qq.com
}

Received 26 October 2016; Accepted 4 January 2017; Published 24 January 2017

Academic Editor: Herminia García Mozo

Copyright (C) 2017 Xiaoqiang Zhang et al. This is an open access article distributed under the Creative Commons Attribution License, which permits unrestricted use, distribution, and reproduction in any medium, provided the original work is properly cited.

\begin{abstract}
Droughts are projected to increase in severity and frequency on both regional and global scales. Despite the increasing occurrence and intensity of the 2009/2010 drought in southwestern China, the impacts of drought on vegetation in this region remain unclear. We examined the impacts of the 2009/2010 drought in southwestern China on vegetation by calculating the standardized anomalies of Normalized Difference Vegetation Index (NDVI), Enhanced Vegetation Index (EVI), Normalized Difference Water Index (NDWI), and Land Surface Temperature (LST). The standardized anomalies of NDVI, EVI, and NDWI exhibited positively skewed frequency distributions, while the standardized anomalies of LST exhibited a negatively skewed frequency distribution. These results implied that the NDVI, EVI, and NDWI declined, while LST increased in the 2009/2010 drought-stricken vegetated areas during the drought period. The responses of vegetation to the 2009/2010 drought differed substantially among biomes. Savannas, croplands, and mixed forests were more vulnerable to the 2009/2010 drought than deciduous forest and grasslands, while evergreen forest was resistant to the 2009/2010 drought in southwestern China. We concluded that the 2009/2010 drought had negative impacts on vegetation in southwestern China. The resulting assessment on the impacts of drought assists in evaluating and mitigating its adverse effects in southwestern China.
\end{abstract}

\section{Introduction}

Drought has increased in severity and frequency over the past decades [1]. Particularly, the 2009/2010 drought in southwestern China was reported as a "once-in-a-century" drought [2]. The occurrence and intensity of the 2009/2010 drought in southwestern China have been highlighted by [3], but the impacts of drought on vegetation in this region remain unclear. Hence, understanding the impacts of this drought is important for assisting in evaluation and prediction of droughts for reducing economic losses in southwestern
China. Previous studies on the impacts of drought on vegetation have mainly focused on Amazon rainforests [4-6], North America [7, 8], Mongolia Plateau [9], and northern China [10-12]. Little research has examined the responses of vegetation to drought in southwestern China.

Satellite-derived vegetation indices (e.g., NDVI and EVI) have been used widely to surrogate the vegetation canopy greenness $[4,13,14]$. Hence, it is vital to investigate the impacts of the 2009/2010 drought on vegetation in subtropical southwestern China using MODIS-derived NDVI and EVI in order to evaluate the responses of vegetation greenness 

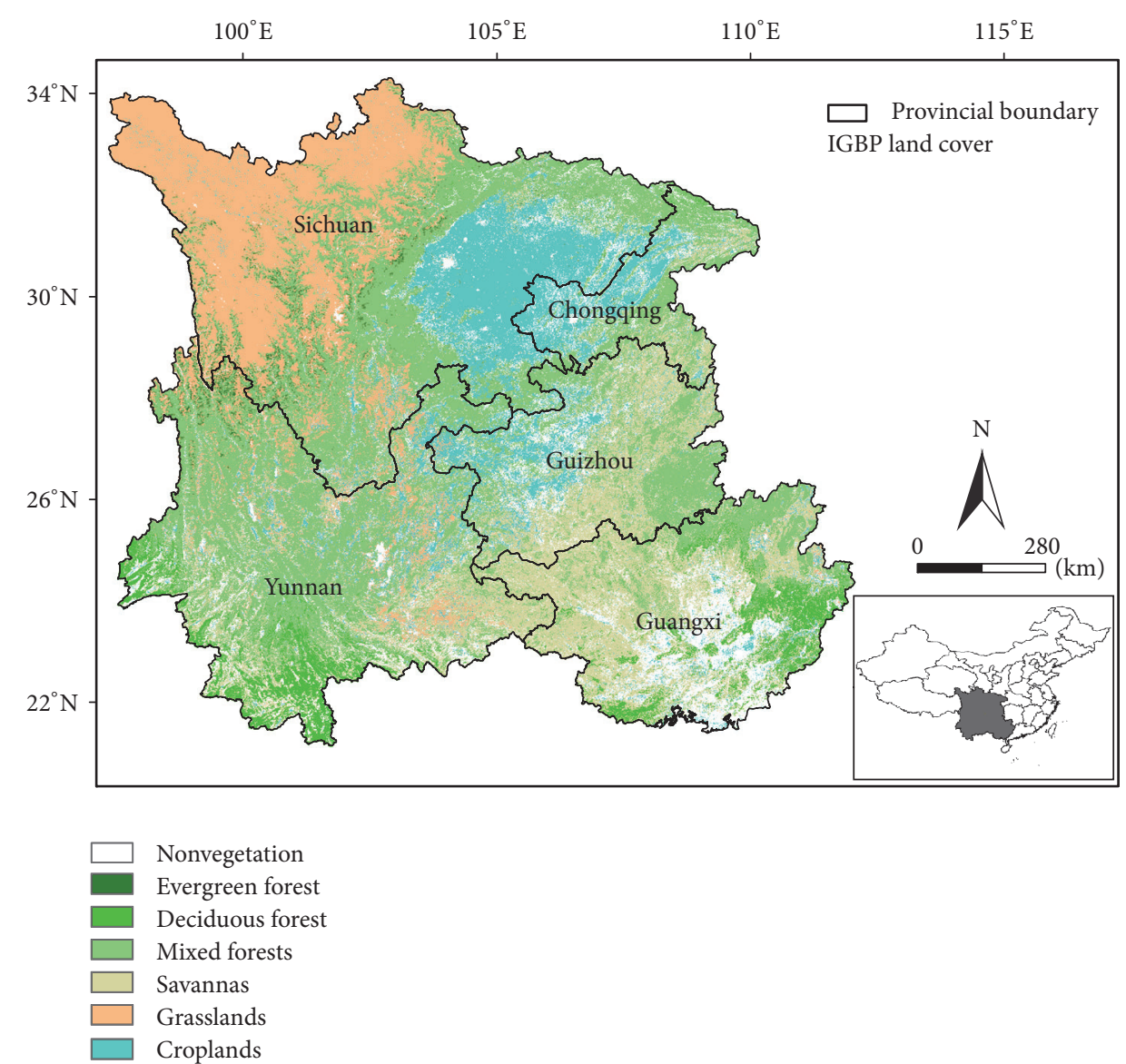

FIGURE 1: Study area. The IGBP land cover classification was based on the MCD12Q1 data of 2008 (Collection 5, $500 \mathrm{~m}$ ).

to drought stress. NDWI reflects changes of spongy mesophyll and water content in vegetation canopies [15]. MODISderived NDWI has been widely used to detect the moisture conditions of vegetation canopies $[16,17]$. MODIS-derived LST is a good indicator of the thermal conditions of the environment [18]. Therefore, the standardized anomalies of MODIS-derived NDWI and LST can reflect the changes in vegetation water content and thermal conditions of the environment, respectively.

In this study, the MODIS-derived NDVI, EVI, NDWI, and LST were proposed as variables for calculating the standardized anomalies to acquire specific information about vegetation greenness, vegetation water content, and land surface temperature, respectively. These variables are significant for examining the responses of vegetation status and thermal conditions of the environment to the 2009/2010 drought quantified by the global terrestrial drought severity index (DSI) [19]. The objective of this study is to assess the responses of vegetation to drought stress in areas of southwestern China that suffered from the 2009/2010 drought.

\section{Study Area}

The study area was located in southwestern China $\left(21^{\circ} \mathrm{N}-\right.$ $35^{\circ} \mathrm{N}, 97^{\circ} \mathrm{E}-113^{\circ} \mathrm{E}$ ), which consists of five provinces: Sichuan,
Chongqing, Guizhou, Guangzhou, and Yunnan (Figure 1). According to the 2008 MODIS land cover data (MCD12Q1), these regions are mainly covered by mixed forests, deciduous forest, evergreen forest, savannas, grasslands, and croplands. The study area is in the subtropical monsoon climate zone [20]. The monthly mean air temperature and annual mean precipitation are approximately $10^{\circ} \mathrm{C}$ and $900 \mathrm{~mm}$, respectively [21].

\section{Data and Processing}

A range of MODIS datasets was used in this study (Table 1). They consist of MODIS vegetation indices (NDVI and EVI) products (MOD13A3) (Collection 5), MODIS surface reflectance product (MOD09A1) (Collection 5), MODIS land surface temperature product (MOD11A2) (Collection 5), and MODIS land cover product (MCD12Q1) (Collection 5) acquired from the US National Aeronautics and Space Administration (NASA) Land Processes Distributed Active Archive Center (LP DAAC) (https://lpdaac.usgs.gov/).

The MOD13A3 (monthly, $1 \mathrm{~km}$ ), MOD09A1 (8-day, $0.5 \mathrm{~km})$, and MOD11A2 (8-day, $1 \mathrm{~km})$ products for the period 2000-2011 were used to calculate the standardized anomalies of vegetation greenness (NDVI and EVI), vegetation water content (NDWI), and land surface temperature (LST) to 
TABLE 1: MODIS datasets used in this study.

\begin{tabular}{lcccc}
\hline Datasets & Period & $\begin{array}{c}\text { Temporal } \\
\text { resolution }\end{array}$ & $\begin{array}{c}\text { Spatial } \\
\text { resolution }\end{array}$ & Resources \\
\hline MOD13A3 & $2000-2011$ & Monthly & $1 \mathrm{~km}$ & LP DAAC \\
MOD09A1 & $2000-2011$ & 8-day & $0.5 \mathrm{~km}$ & LP DAAC \\
MOD11A2 & $2000-2011$ & 8 -day & $1 \mathrm{~km}$ & LP DAAC \\
MCD12Q1 & 2008 & Annual & $0.5 \mathrm{~km}$ & LP DAAC \\
DSI & $2000-2011$ & 8-day & $0.05^{\circ}$ & NTSG \\
\hline
\end{tabular}

examine the effects of the 2009/2010 drought on vegetation in southwestern China, respectively. These MODIS products were aggregated into a monthly interval by calculating the average value over the corresponding period and then resampled at a $0.05^{\circ}$ spatial resolution to maintain the same temporal and spatial resolutions for different types of datasets.

The 2008 MODIS land cover product (MCD12Q1) was used to locate different vegetation types in the study area: deciduous forest, evergreen forest, mixed forests, croplands, grasslands, and savannas. Other land cover classes, such as water, urban and built-up, barren or sparsely vegetated, were aggregated as nonvegetation.

The global terrestrial drought severity index (DSI) products were generated by [19] to monitor the global terrestrial drought for the period 2000-2011 by integrating the MODIS-derived NDVI and Evapotranspiration/Potential Evapotranspiration (ET/PET) data. The reasons of choosing DSI as a standard to evaluate the results from different RS-based indices are the following: (1) DSI has advantages in high spatial resolution with 0.05 degrees comparing to meteorological-based drought index such as Palmer Drought Severity Index (PDSI) with 0.25 degrees [22]; (2) DSI could be more sensitive to drought stress comparing to other remotely sensed drought indexes such as Vegetation Condition Index (VCI), which is driven only by NDVI $[23,24]$, as DSI is designed to detect the anomalies of photosynthetic activity of vegetation conditions, evapotranspiration and potential evapotranspiration of soil and vegetation activities under the stress of drought [19]; (3) this study is a further work following the previous one by Zhang and Yamaguchi [3]. So we used the same drought severity index (DSI) to evaluate the impacts of a serious drought event on vegetation over southwestern China.

DSI data was acquired from the Numerical Terradynamical Simulation Group (NTSG) at the University of Montana (http://files.ntsg.umt.edu/data/NTSG_Products/DSI/). In this study, the DSI products at 8-day intervals with $0.05^{\circ}$ spatial resolution from 2000 to 2011 were composited to a monthly interval to characterize the extent, duration, and severity of the 2009/2010 drought in southwestern China. The DSI values less than or equal to -0.3 were categorized as drought [19]. Monthly DSI values for the drought period from November 2009 to March 2010 were averaged to represent the dry period mean of the $2009 / 2010$ drought in southwestern China.

Our study area $\left(21^{\circ} \mathrm{N}-35^{\circ} \mathrm{N}, 97^{\circ} \mathrm{E}-113^{\circ} \mathrm{E}\right)$ was covered by five tiles of MODIS images. The MODIS tile numbers are h26v05, h26v06, h28v06, h27v05, and h27v06. Five tiles of original MODIS images (MOD13A3, MOD09A1, and MOD11A2) were mosaicked and cut using MODIS Reprojection Tool (MRT) developed by NASA.

\section{Methodology}

4.1. Calculating the Standardized Anomaly (SA). The standardized anomalies (SAs) of NDVI, EVI, NDWI, and LST are calculated as

$$
\mathrm{SA}=\frac{X-M}{S},
$$

where SA is a given variable (e.g., NDVI, EVI, NDWI, and LST) calculated from its value for the 2009/2010 drought period $(X)$ relative to long-term mean $(M)$ and standard deviation (S) over a reference period. The 2009/2010 drought period for southwestern China was characterized by [3] as "November 2009 to March 2010." Thus, in this study, the monthly MODIS composites (NDVI, EVI, NDWI, and LST) were averaged for November, December, January, February, and March to represent the dry period mean for each year over the reference period 2000-2011, but excluding the 2009/ 2010 drought period.

In this study, only vegetated areas that suffered from the 2009/2010 drought were selected for calculating the standardized anomalies. Regions labeled "no drought" (DSI equal to or higher than -0.29) and "no data" (see Figure 2) were excluded.

4.2. Evaluating the Impacts of 2009/2010 Drought on Vegetation in Southwestern China. The impacts of the 2009/2010 drought on vegetation in southwestern China were evaluated and analyzed using monthly averaged standardized anomalies of NDVI, EVI, NDWI, and LST. They were first calculated pixel by pixel for vegetated areas affected by the 2009/2010 drought quantified by DSI during the drought; then frequency histograms of the standardized anomalies of NDVI, EVI, NDWI, and LST were generated; finally, nonlinear curves of the frequency histograms of the standardized anomalies for NDVI, EVI, NDWI, and LST were fitted by a Gaussian function to show the skewed frequency distributions.

The NDVI, EVI, NDWI, and LST were used as RS-based indices to compare with DSI in this study. Pearson's coefficient $(r)$ and $p$ value were used to evaluate the relationships between DSI and standardized anomalies of NDVI, EVI, NDWI, and LST for different biomes. Noticeably, NDVI is one of driving parameters for DSI, which is a little different from that used for calculating the standardized anomaly of NDVI in this study. As the former one is only for growing season, the latter one is based on whole season.

\section{Results and Discussion}

5.1. The 2009/2010 Drought Quantified by the MODIS-Derived DSI. Distribution of the drought in southwestern China as detected by DSI is shown in Figure 2. Spatially, western Guizhou, central and eastern Yunnan, and western Guangxi 


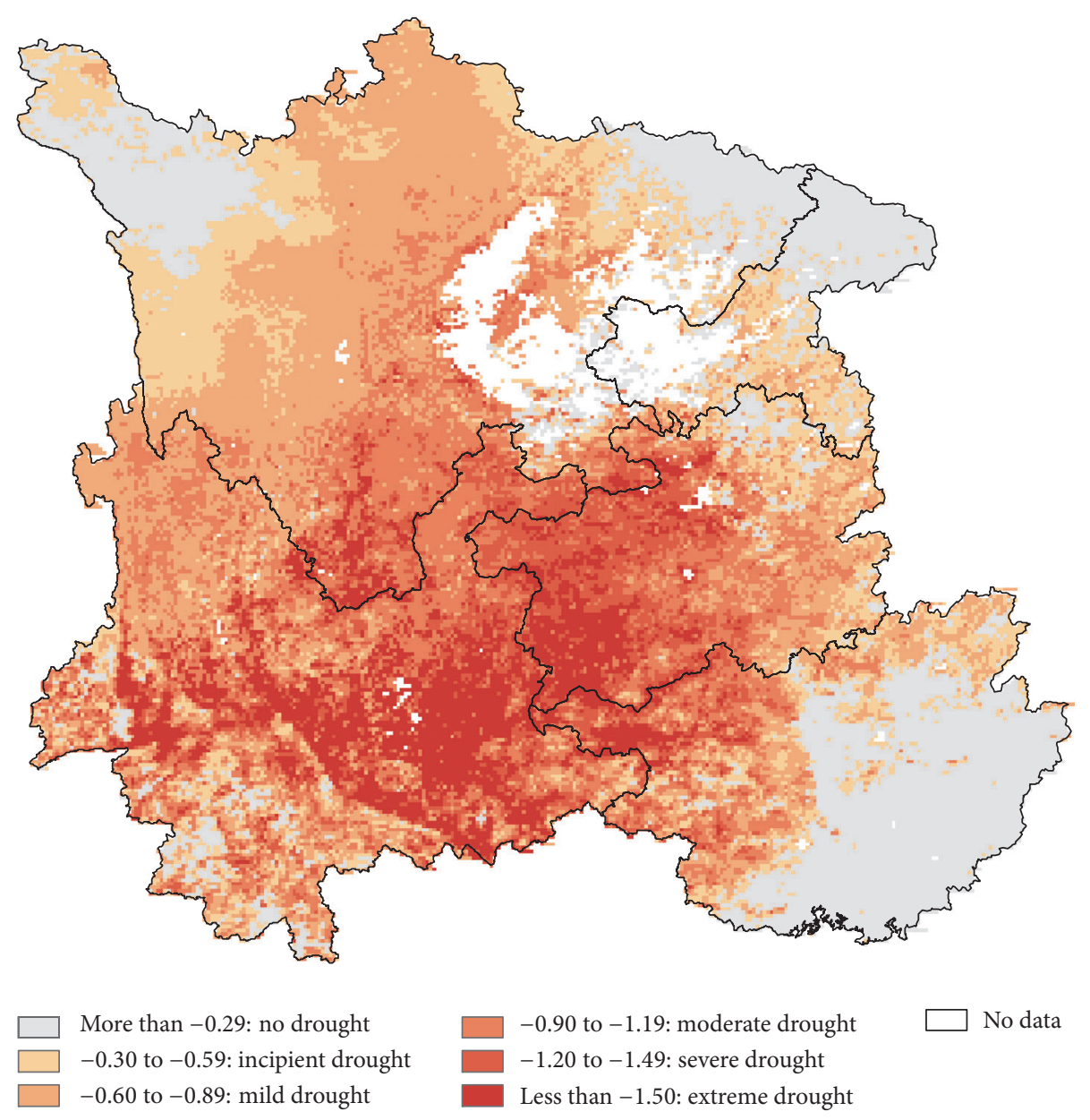

FIGURE 2: Distribution of the drought as detected by the averaged monthly DSI from November 2009 to March 2010 over southwestern China.

experienced moderate to extreme drought, showing higher drought stress in the drought-stricken regions (Figure 2). Nondrought areas were mainly distributed in the horns of northwestern Sichuan, northeastern Sichuan, and Chongqing, as well as south and east of Guangxi (Figure 2).

As shown in Figure 2, 74.4\% of the study area experienced drought whose intensities ranged from incipient to extreme. Percentages of areas that experienced incipient, mild, moderate, severe, and extreme drought were $14.6 \%, 11.7 \%, 14.9 \%$, $16.3 \%$, and $16.9 \%$, respectively (Figure 3 ).

\subsection{Spatial Distribution of Standardized Anomalies for NDVI,} EVI, NDWI, and LST. Figure 4 shows the spatial distributions of standardized anomalies of NDVI, EV, NDWI, and LST in vegetated areas that suffered from the 2009/2010 drought. The spatial patterns of standardized anomalies varied among NDVI, EVI, NDWI, and LST, as well as among different drought-stricken regions.

For both NDVI and EVI during the drought period, areas experiencing negative anomalies had similar spatial distributions in central and eastern Yunnan, parts of southern Sichuan and western Guizhou, and northern Sichuan, which suffered from moderate to extreme drought (Figures 4(a) and

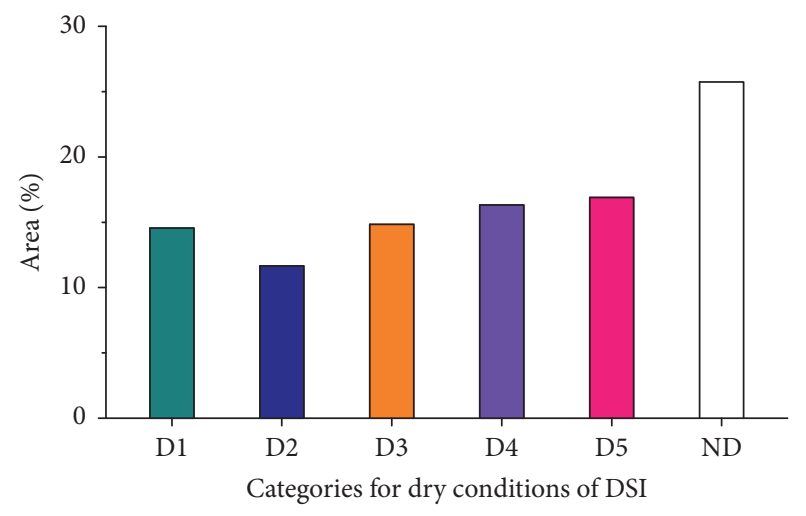

FIGURE 3: Drought areas quantified by the averaged monthly DSI from November 2009 to March 2010. D1 = incipient drought; D2 = mild drought; D3 = moderate drought; D4 = severe drought; D5 = extreme drought; ND = no drought.

4(b)). It was implied that the vegetation greenness (NDVI and EVI) declined in those drought-stricken regions during the drought period. We found that the spatial distributions of standardized anomalies of NDVI corresponded favorably 

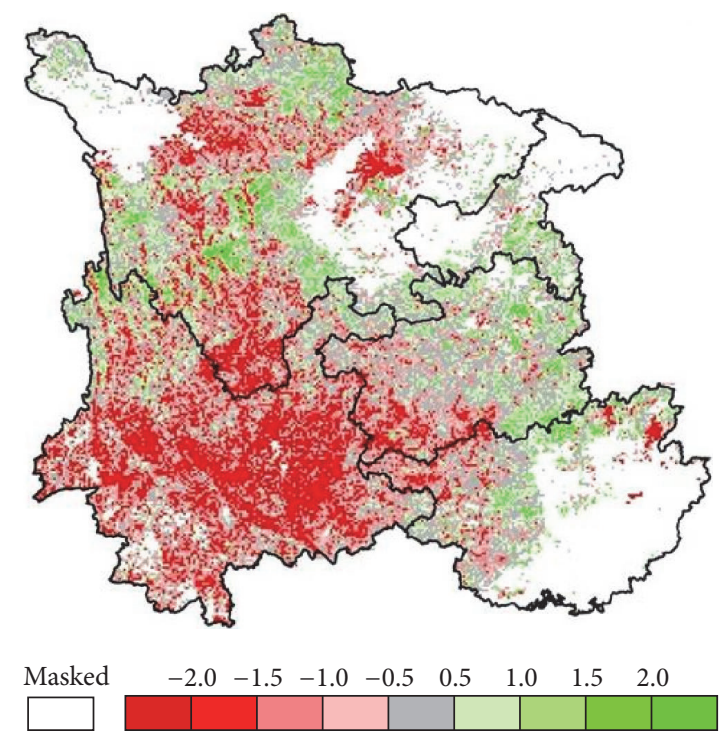

(a)
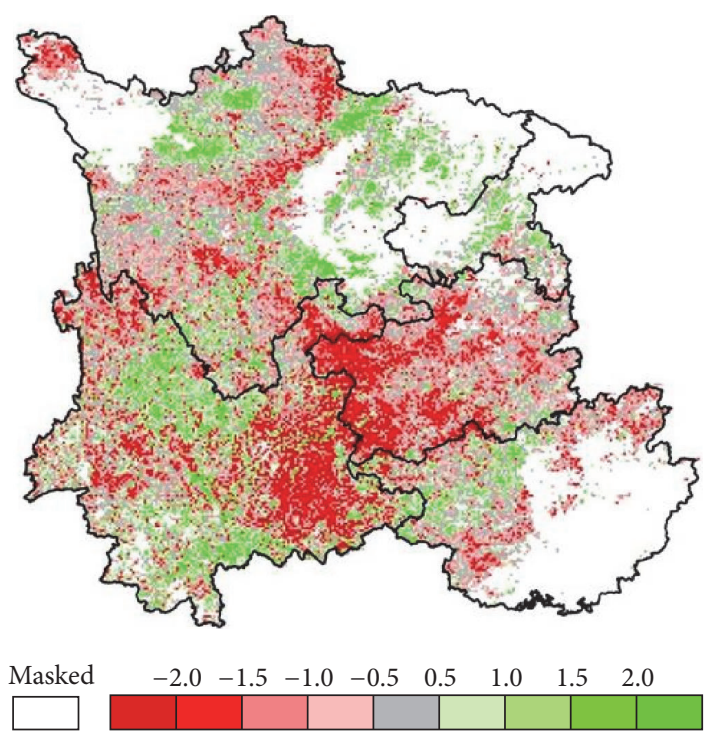

(c)

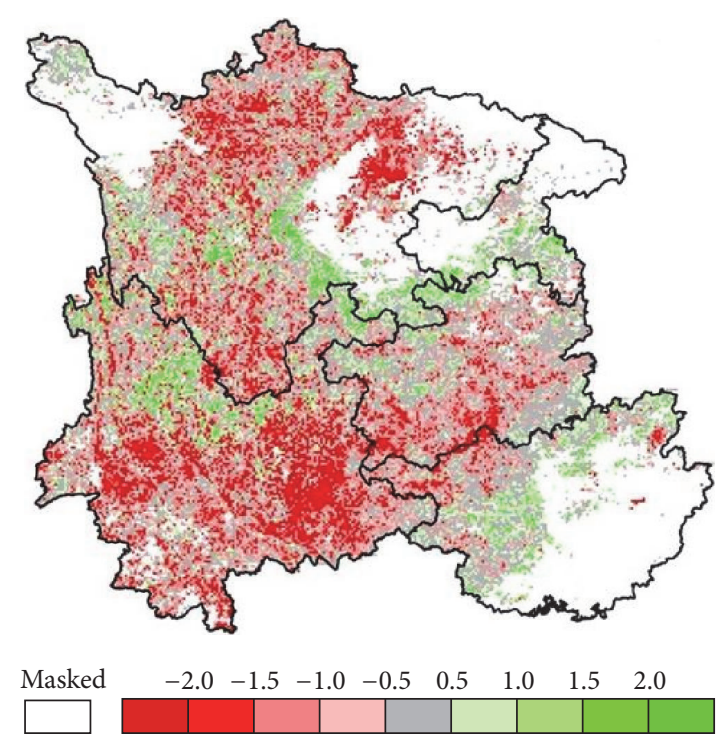

(b)

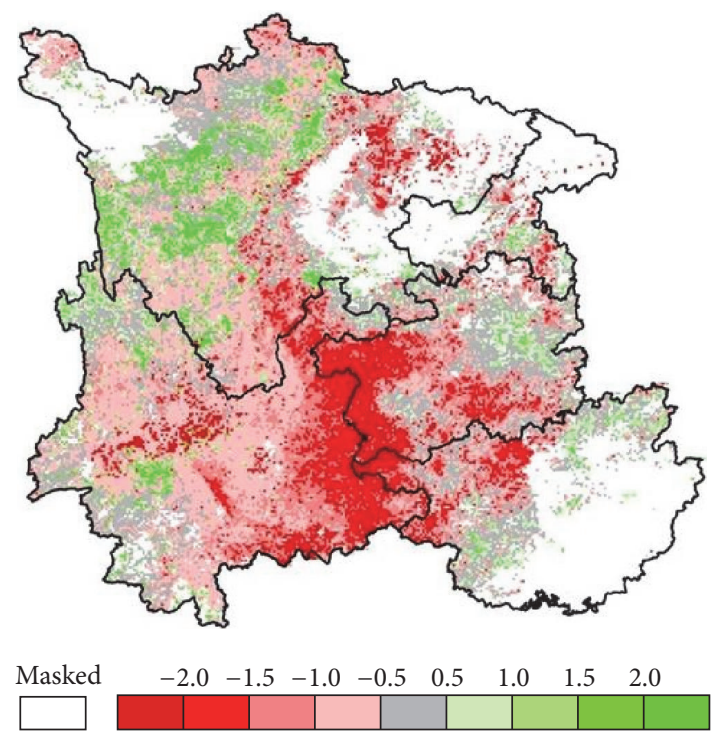

(d)

FIGURE 4: Spatial distributions of standardized anomalies: (a) for NDVI, (b) for EVI, (c) for NDWI, and (d) for LST during the drought period in vegetated areas, which suffered from the 2009/2010 drought over southwestern China.

with the distributions of drought, in comparison with the EVI for overall distribution trends, implying that standardized anomalies of NDVI were more sensitive to the 2009/2010 drought than standardized anomalies of EVI in southwestern China (Figures 2, 4(a), and 4(b)).

The areas experiencing negative anomalies of NDWI were smaller than those of NDVI and EVI, which were mainly distributed in the eastern Yunnan, western Guizhou, and central Sichuan, which suffered from moderate to extreme drought (Figure 4(c)). In comparison, areas experiencing positive anomalies of NDWI were distributed more widely than those of NDVI and EVI, indicating that the greenness of vegetation (NDVI and EVI) was more easily affected by the 2009/2010 drought than vegetation water content (NDWI), especially in central and western Yunnan (Figures 2, 4(a), $4(\mathrm{~b})$, and $4(\mathrm{c}))$. It is notable that the results of NDWI were contradictory with NDVI, EVI, and LST in some areas of eastern Sichuan (croplands) and southern Yunnan (deciduous forests). The reasons concerning in this phenomenon were unknown (Figures 4(a), 4(b), and 4(c)).

The areas experiencing positive anomalies for LST included most areas of Yunnan, western Guangzhou, and southern Sichuan, which suffered from mild to extreme drought (Figure 4(d)). It was implied that the LST increased in those drought-stricken areas due to the 2009/2010 drought. Particularly, there were extreme droughts in areas bordering Yunnan and Guizhou, where positive anomalies were greatest for LST (Figures 2 and 4(d)). 


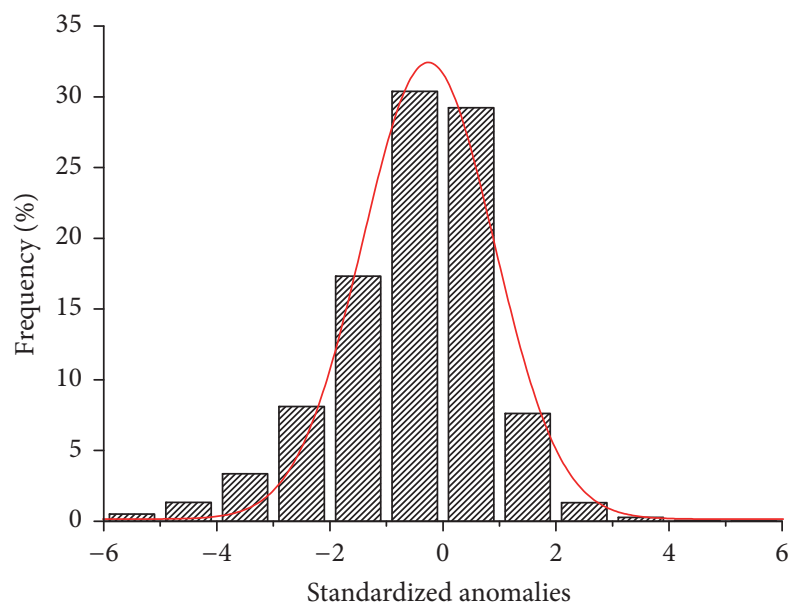

(a)

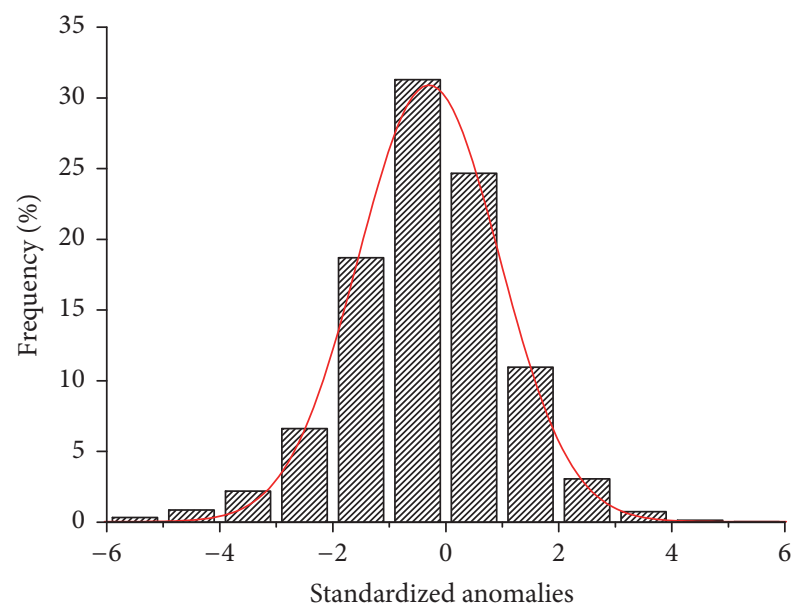

(c)

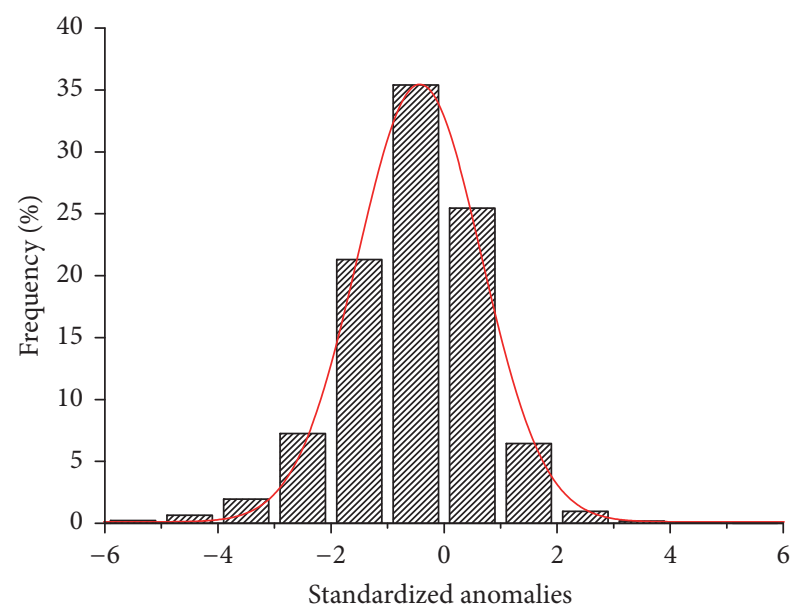

(b)

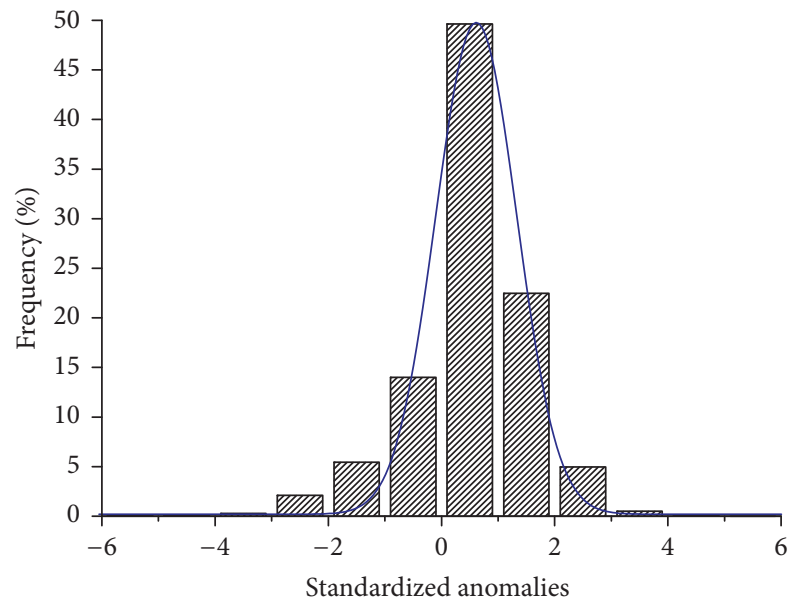

(d)

FIGURE 5: Frequency distributions of standardized anomalies: (a) for NDVI, (b) for EVI, (c) for NDWI, and (d) for LST during the drought period in vegetated areas, which suffered from the 2009/2010 drought over southwestern China.

5.3. Frequency Distributions of Standardized Anomalies for NDVI, EVI, NDWI, and LST. To examine the impacts of the $2009 / 2010$ drought on vegetation, we generated frequency histograms of standardized anomalies of NDVI, EVI, NDWI, and LST (Figure 5). We found that the standardized anomalies of NDVI, EVI, and NDWI exhibited positively skewed frequency distributions with the peak values between -1 and 0 (Figures 5(a), 5(b), and 5(c)), while the standardized anomalies of LST exhibited a negatively skewed frequency distribution with the peak value between 0 and 1 (Figure $5(\mathrm{~d})$ ). Both the vegetation greenness (NDVI and EVI) and vegetation water content (NDWI) declined, while the land surface temperature (LST) increased in the 2009/2010 drought-stricken vegetated areas, implying that the 2009/ 2010 drought had negative impacts on vegetation in southwestern China.

5.4. Relationships between DSI and Standardized Anomalies of NDVI, EVI, NDWI, and LST. Figure 6 shows the relationships between DSI and standardized anomalies of NDVI, EVI, NDWI, and LST during the drought period. We found that the standardized anomalies of NDVI $(r=0.415, p<$ 0.01 ) (Figure 6(a)), EVI $(r=0.309, p<0.01$ ) (Figure 6(b)), and NDWI $(r=0.286, p<0.01)$ (Figure $6(\mathrm{c})$ ) had positive correlations with DSI, while LST $(r=-0.226, p<0.01)$ (Figure 6(d)) had a negative correlation with DSI during the drought period in southwestern China, implying that the 2009/2010 drought reduced NDVI, EVI, and NDWI but increased LST in southwestern China. It is notable that the plots when DSI is equal to or higher than -0.29 were masked in order to calculate the standardized anomalies of RS-based indices in vegetated areas, which suffered from the 2009/2010 drought over southwestern China. In other words, only the pixels when DSI is equal to or lower than -0.30 (drought) were included in this study; others were masked.

5.5. Reponses of Vegetation Types to the 2009/2010 Drought. Our study regions were mainly covered by mixed forests, deciduous forest, evergreen forest, savannas, grasslands, and croplands (Figure 1). We intended to analyze the effects of the 2009/2010 drought for different types of vegetation in 


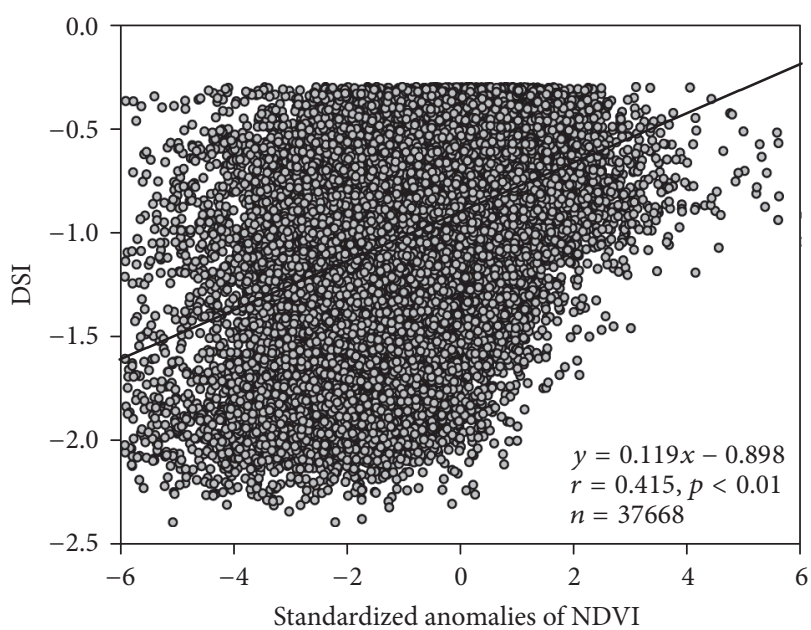

(a)

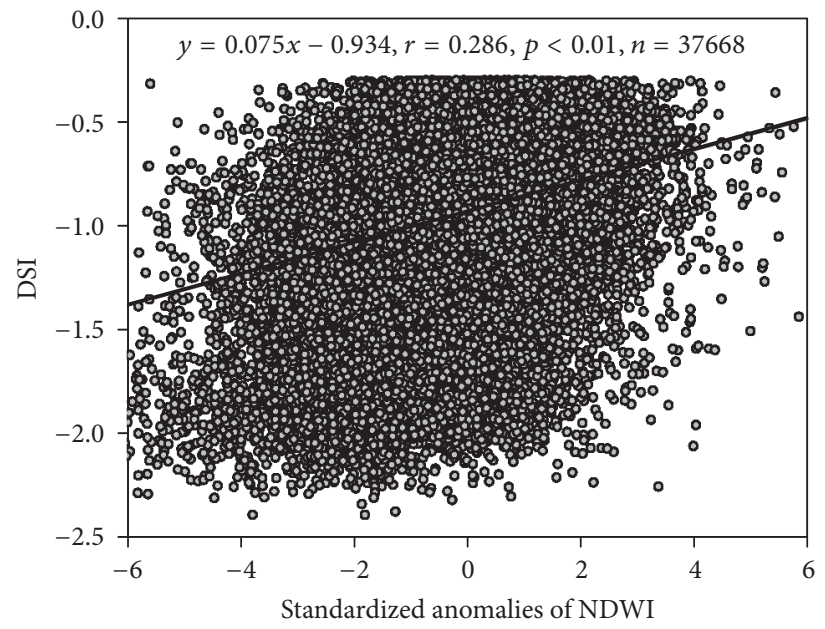

(c)

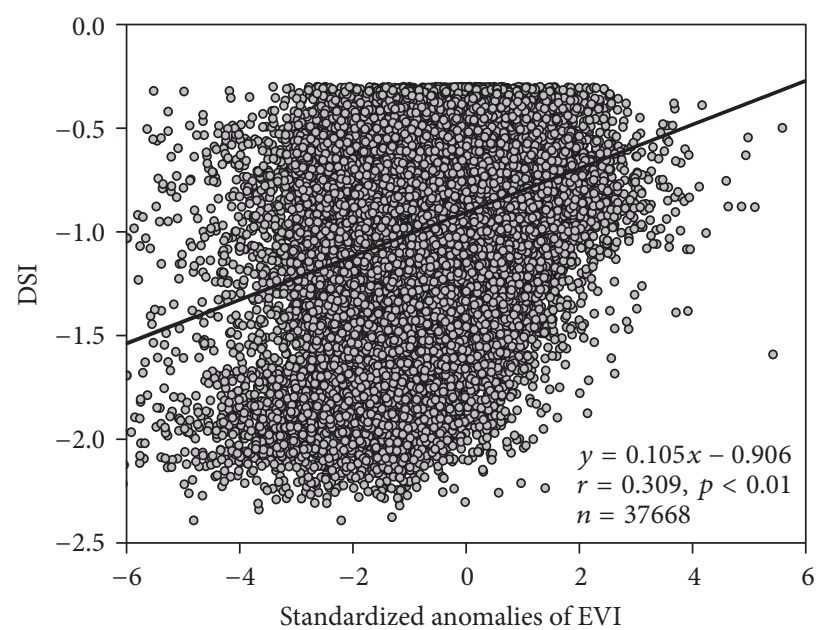

(b)

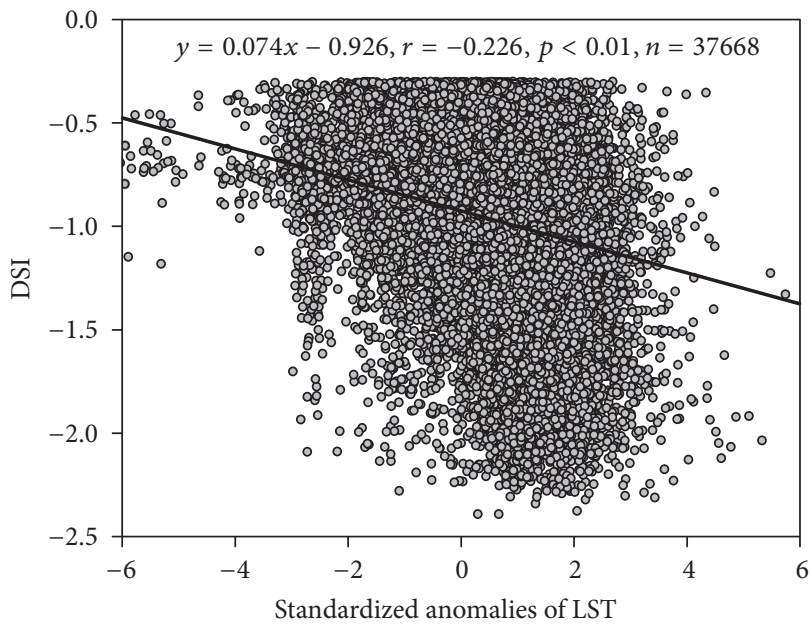

(d)

Figure 6: Relationships between DSI and standardized anomalies: (a) for NDVI, (b) for EVI, (c) for NDWI, and (d) for LST during the drought period in vegetated areas, which suffered from the 2009/2010 drought over southwestern China.

southwestern China. We found that responses of vegetation to the 2009/2010 drought varied among different biomes.

Forest ecosystems showed complex patterns in their responses to the 2009/2010 drought. Among the mixed forests, deciduous forest and evergreen forest, negative anomalies of NDVI and EVI were the greatest for the mixed forests in central and western Yunnan that suffered from severe to extreme drought (Figures 1, 2, and 4). It was indicated that the 2009/2010 drought-induced greenness of mixed forests declined substantially. The standardized anomalies of NDVI $(r=0.432, p<0.01)$, EVI $(r=0.302, p<0.01)$, and NDWI $(r=0.207, p<0.01)$ had positive correlations with DSI, while LST $(r=-0.222, p<0.01)$ had a negative correlation with DSI for mixed forests (Figure 7). More than half of the areas with deciduous forest did not experience the 2009/2010 drought (Figures 1 and 2); the standardized anomalies of NDVI $(r=0.2592, p<0.01)$, EVI $(r=0.210$, $p<0.01)$, and NDWI $(r=0.134, p<0.01)$ had positive correlations with DSI, while no relationship was identified between LST and DSI (Figure 7). In comparison with mixed forests and deciduous forest, evergreen forest exhibited different response patterns to the 2009/2010 drought, and the standardized anomalies of NDWI $(r=0.130, p<0.01)$ had a positive correlation with DSI, while NDVI $(r=-0.186$, $p<0.01)$, EVI $(r=-0.104, p<0.01)$, and LST $(r=-0.135$, $p<0.01$ ) had negative correlations with DSI (Figure 7). It was suggested that the 2009/2010 drought reduced NDWI but increased NDVI, EVI, and LST for evergreen forest.

Grasslands were mainly distributed in north and west Sichuan, which suffered from incipient to mild drought, except for the horn of northwestern Sichuan (no drought) (Figures 1, 2, and 4). The standardized anomalies of NDVI $(r=0.294, p<0.01)$, EVI $(r=0.212, p<0.01)$, and NDWI $(r=0.263, p<0.01)$ had positive correlations with DSI, while LST $(r=-0.239, p<0.01)$ had a negative correlation with DSI for grasslands (Figure 7).

Areas experiencing the greatest negative anomalies of NDWI and positive anomalies of LST were covered by mixes of croplands, savannas, and mixed forests and found bordering Yunnan, Guizhou, and Guangxi, which suffered from 


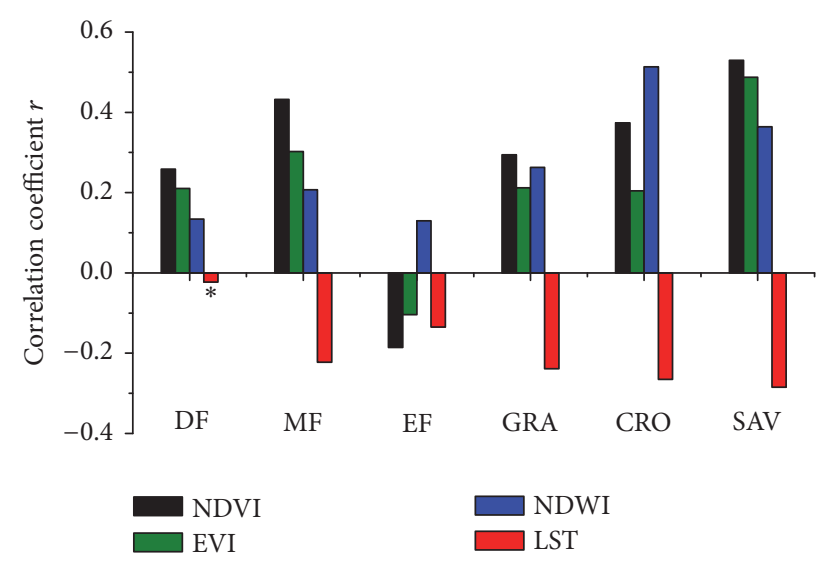

FIGURE 7: Correlation coefficients between monthly DSI values and the standardized anomalies of NDVI, EVI, NDWI, and LST in vegetated areas, which suffered from the 2009/2010 drought for different plant function types. $p$ value $<0.01$, except for those marked with an asterisk $(*) . \mathrm{DF}=$ deciduous forest; $\mathrm{MF}=$ mixed forests; $\mathrm{EF}=$ evergreen forest; GRA = grasslands; $\mathrm{CRO}=$ croplands; $\mathrm{SAV}=$ savannas.

mild to extreme drought (Figures 1, 2, and 4). The 2009/2010 drought-induced vegetation water content of croplands, savannas, shrublands, and mixed forests declined, while LST increased in those regions. Standardized anomalies of NDVI $(r=0.530, p<0.01)$, EVI $(r=0.487, p<0.01)$, and NDWI $(r=0.364, p<0.01)$ had positive correlations with DSI, while LST $(r=-0.285, p<0.01)$ had a negative correlation with DSI for savannas, implying that the 2009/2010 drought reduced NDVI, EVI, and NDWI but increased LST for savannas (Figure 7). For croplands, standardized anomalies of NDVI $(r=0.374, p<0.01)$, EVI $(r=0.205, p<0.01)$, and NDWI $(r=0.513, p<0.01)$ had positive correlations with DSI, while LST $(r=-0.265, p<0.01)$ had a negative correlation with DSI, implying that the water content of croplands was reduced largely due to the 2009/2010 drought in comparison with other biomes (Figure 7).

For different biomes in our study area, the savannas were most affected by the 2009/2010 drought quantified by DSI, which had the highest positive correlations with standardized anomalies of NDVI and EVI, but the highest negative correlation with LST. The largest proportions of areas for savannas experienced declines in NDVI and EVI and an increase in LST. DSI had positive correlations with standardized anomalies of NDVI and EVI, but a lower negative correlation with LST, indicating that evergreen forest was less affected by the 2009/2010 drought. Hence, evergreen forest was resistant to the 2009/2010 drought in southwestern China compared with other biomes. The largest positive correlation between DSI and NDWI was seen for croplands, implying that the largest proportions of areas for croplands experienced a decline in NDWI during the 2009/2010 drought.

Our results suggested that the responses of vegetation to the 2009/2010 drought differed substantially among different biomes. Savannas, croplands, and mixed forests were more vulnerable to the 2009/2010 drought than deciduous forest and grasslands, while evergreen forest was resistant to the
2009/2010 drought in southwestern China. The possible reasons of different drought resistances for vegetation types lie in the following: forests were more resistant to this extreme drought than croplands and savannas because trees were generally able to have great access to ground water with deeper roots.

\section{Conclusion}

We assessed the severity of the 2009/2010 drought using MODIS-derived DSI data and examined the vegetation response to this extreme event using standardized anomalies of NDVI, EVI, NDWI, and LST derived from MODIS data for the period 2000-2011. We found that (1) NDVI, EVI, and NDWI decreased, while LST increased in the 2009/2010 drought-stricken vegetated areas in southwestern China, as shown by the skewed frequency distributions of standardized anomalies of NDVI, EVI, NDWI, and LST; (2) the standardized anomalies of NDVI, EVI, and NDWI had positive correlations with DSI, while LST had a negative correlation with DSI; (3) responses of vegetation to the 2009/2010 drought varied among biomes: savannas, croplands, and mixed forests were more vulnerable to the 2009/2010 drought than deciduous forest and grasslands, while evergreen forest was resistant to the 2009/2010 drought. We concluded that the 2009/2010 drought had negative impacts on vegetation in southwestern China.

There is a need to further investigate the response of croplands to the 2009/2010 drought using other drought indices, such as the vegetation water thermal stress index (VWTCI) [25], as there is a lack of DSI data for cropland cover in southeastern Sichuan and southwestern Chongqing. Further study should focus on comparing the responses of vegetation indices and LST to drought and soil moisture in dry period and wet period [26-32].

\section{Competing Interests}

The authors declare no conflict of interests.

\section{Acknowledgments}

This study was financially supported by the China Scholarship Council (CSC) and also sponsored by the National Natural Science Foundation of China (nos. 41471460, 41130750), the "One Hundred Talents Program" of the Chinese Academy of Sciences (no. Y5BR011001), and the Natural Science Foundation of Jiangsu Province (BK20151060). The authors thank the Land Processes Distributed Active Archive Center (LP DAAC) and Numerical Terradynamical Simulation Group (NTSG) at the University of Montana for providing the MODIS datasets.

\section{References}

[1] P. Y. Groisman, E. A. Clark, D. P. Lettenmaier et al., "The northern Eurasia earth science partnership: an example of science applied to societal needs," Bulletin of the American Meteorological Society, vol. 90, no. 5, pp. 671-688, 2009. 
[2] J. Yang, D. Gong, W. Wang, M. Hu, and R. Mao, "Extreme drought event of 2009/2010 over southwestern China," Meteorology and Atmospheric Physics, vol. 115, no. 3-4, pp. 173-184, 2012.

[3] X. Q. Zhang and Y. Yamaguchi, "Characterization and evaluation of MODIS-derived drought severity index (DSI) for monitoring the 2009/2010 drought over southwestern China," Natural Hazards, vol. 74, no. 3, pp. 2129-2145, 2014.

[4] A. R. Huete, K. Didan, Y. E. Shimabukuro et al., "Amazon rainforests green-up with sunlight in dry season," Geophysical Research Letters, vol. 33, no. 6, Article ID L06405, 2006.

[5] S. L. Lewis, P. M. Brando, O. L. Phillips, G. M. F. Van Der Heijden, and D. Nepstad, "The 2010 Amazon drought," Science, vol. 331, no. 6017, p. 554, 2011.

[6] L. Xu, A. Samanta, M. H. Costa, S. Ganguly, R. R. Nemani, and R. B. Myneni, "Widespread decline in greenness of Amazonian vegetation due to the 2010 drought," Geophysical Research Letters, vol. 38, no. 7, Article ID L07402, 2011.

[7] X. Zhang, M. Goldberg, D. Tarpley et al., "Drought-induced vegetation stress in southwestern North America," Environmental Research Letters, vol. 5, no. 2, Article ID 024008, 2010.

[8] L. Ji and A. J. Peters, "Assessing vegetation response to drought in the northern Great Plains using vegetation and drought indices," Remote Sensing of Environment, vol. 87, no. 1, pp. 85-98, 2003.

[9] R. John, J. Chen, Z.-T. Ou-Yang et al., "Vegetation response to extreme climate events on the Mongolian Plateau from 2000 to 2010," Environmental Research Letters, vol. 8, no. 3, Article ID 035033, 2013.

[10] L. Du, Q. Tian, T. Yu et al., "A comprehensive drought monitoring method integrating MODIS and TRMM data," International Journal of Applied Earth Observation and Geoinformation, vol. 23, no. 1, pp. 245-253, 2013.

[11] J. Wu, L. Zhou, M. Liu, J. Zhang, S. Leng, and C. Diao, "Establishing and assessing the Integrated Surface Drought Index (ISDI) for agricultural drought monitoring in mid-eastern China," International Journal of Applied Earth Observation and Geoinformation, vol. 23, no. 1, pp. 397-410, 2013.

[12] A. Zhang and G. Jia, "Monitoring meteorological drought in semiarid regions using multi-sensor microwave remote sensing data," Remote Sensing of Environment, vol. 134, pp. 12-23, 2013.

[13] R. B. Myneni, F. G. Hall, P. J. Sellers, and A. L. Marshak, "Interpretation of spectral vegetation indexes," IEEE Transactions on Geoscience and Remote Sensing, vol. 33, no. 2, pp. 481-486, 1995.

[14] R. B. Myneni, C. D. Keeling, C. J. Tucker, G. Asrar, and R. R. Nemani, "Increased plant growth in the northern high latitudes from 1981 to 1991," Nature, vol. 386, no. 6626, pp. 698-702, 1997.

[15] B.-C. Gao, "NDWI-a normalized difference water index for remote sensing of vegetation liquid water from space," Remote Sensing of Environment, vol. 58, no. 3, pp. 257-266, 1996.

[16] M. Maki, M. Ishiahra, and M. Tamura, "Estimation of leaf water status to monitor the risk of forest fires by using remotely sensed data," Remote Sensing of Environment, vol. 90, no. 4, pp. 441-450, 2004.

[17] D. Chen, J. Huang, and T. J. Jackson, "Vegetation water content estimation for corn and soybeans using spectral indices derived from MODIS near- and short-wave infrared bands," Remote Sensing of Environment, vol. 98, no. 2-3, pp. 225-236, 2005.

[18] Z. Wan, Y. Zhang, Q. Zhang, and Z.-L. Li, "Quality assessment and validation of the MODIS global land surface temperature," International Journal of Remote Sensing, vol. 25, no. 1, pp. 261274, 2004.
[19] Q. Mu, M. Zhao, J. S. Kimball, N. G. McDowell, and S. W. Running, "A remotely sensed global terrestrial drought severity index," Bulletin of the American Meteorological Society, vol. 94, no. 1, pp. 83-98, 2013.

[20] L. Zhang, J. F. Xiao, J. Li, K. Wang, L. Lei, and H. Guo, “The 2010 spring drought reduced primary productivity in southwestern China," Environmental Research Letters, vol. 7, no. 4, Article ID 045706, 2012.

[21] H. Wang, H. Lin, and D. Liu, "Remotely sensed drought index and its responses to meteorological drought in Southwest China," Remote Sensing Letters, vol. 5, no. 5, pp. 413-422, 2014.

[22] G. Van Der Schrier, J. Barichivich, K. R. Briffa, and P. D. Jones, "A scPDSI-based global data set of dry and wet spells for 19012009," Journal of Geophysical Research Atmospheres, vol. 118, no. 10, pp. 4025-4048, 2013.

[23] F. N. Kogan, "Application of vegetation index and brightness temperature for drought detection," Advances in Space Research, vol. 15, no. 11, pp. 91-100, 1995.

[24] F. N. Kogan, "Global drought watch from space," Bulletin of the American Meteorological Society, vol. 78, no. 4, pp. 621-636, 1997.

[25] N. Shakya and Y. Yamaguchi, "Vegetation, water and thermal stress index for study of drought in Nepal and central northeastern India," International Journal of Remote Sensing, vol. 31, no. 4, pp. 903-912, 2010.

[26] A. AghaKouchak, A. Farahmand, F. S. Melton et al., "Remote sensing of drought: progress, challenges and opportunities," Reviews of Geophysics, vol. 53, no. 2, pp. 452-480, 2015.

[27] Z.-L. Li, B.-H. Tang, H. Wu et al., "Satellite-derived land surface temperature: current status and perspectives," Remote Sensing of Environment, vol. 131, pp. 14-37, 2013.

[28] P. Leng, X. Song, Z.-L. Li, J. Ma, F. Zhou, and S. Li, "Bare surface soil moisture retrieval from the synergistic use of optical and thermal infrared data," International Journal of Remote Sensing, vol. 35, no. 3, pp. 988-1003, 2014.

[29] A. Scaini, N. Sánchez, S. M. Vicente-Serrano, and J. MartínezFernández, "SMOS-derived soil moisture anomalies and drought indices: a comparative analysis using in situ measurements," Hydrological Processes, vol. 29, no. 3, pp. 373-383, 2015.

[30] J. Martínez-Fernández, A. González-Zamora, N. Sánchez, A. Gumuzzio, and C. M. Herrero-Jiménez, "Satellite soil moisture for agricultural drought monitoring: assessment of the SMOS derived Soil Water Deficit Index," Remote Sensing of Environment, vol. 177, pp. 277-286, 2016.

[31] N. Sánchez, Á. González-Zamora, M. Piles, and J. MartínezFernández, "A new Soil Moisture Agricultural Drought Index (SMADI) integrating MODIS and SMOS products: a case of study over the Iberian Peninsula," Remote Sensing, vol. 8, no. 4, pp. 287-312, 2016.

[32] L. Zhang, W. Jiao, H. Zhang, C. Huang, and Q. Tong, "Studying drought phenomena in the Continental United States in 2011 and 2012 using various drought indices," Remote Sensing of Environment, vol. 190, pp. 96-106, 2017. 

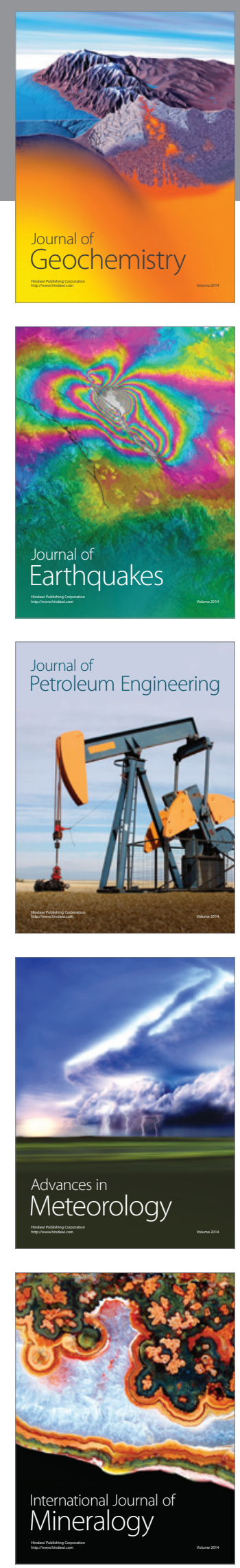
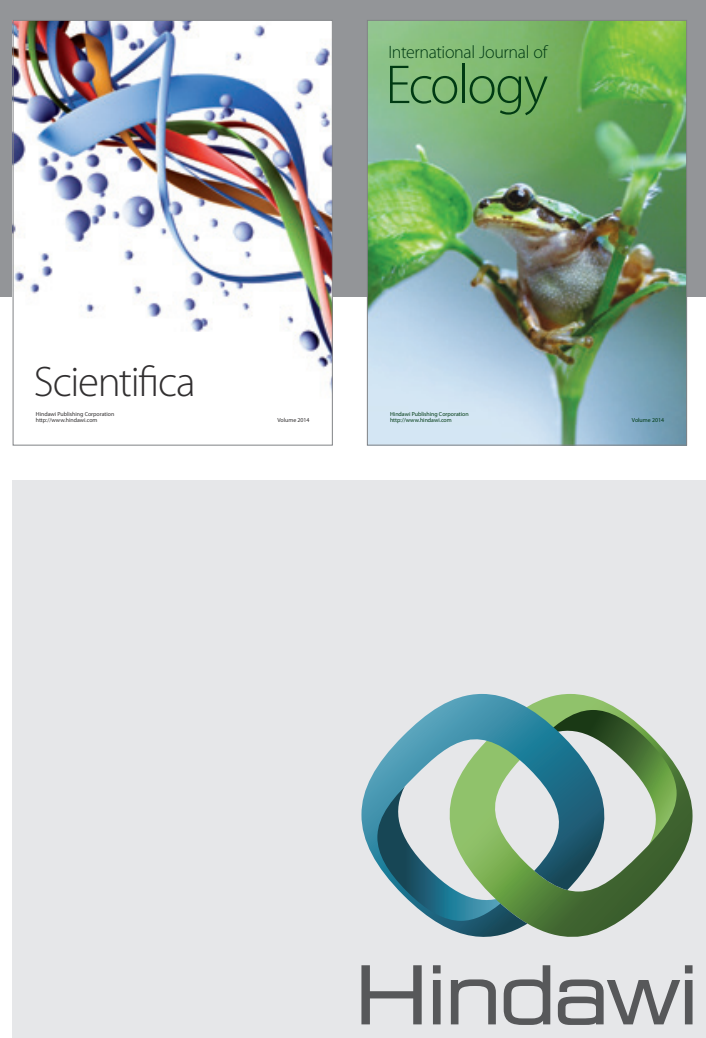

Submit your manuscripts at

https://www.hindawi.com
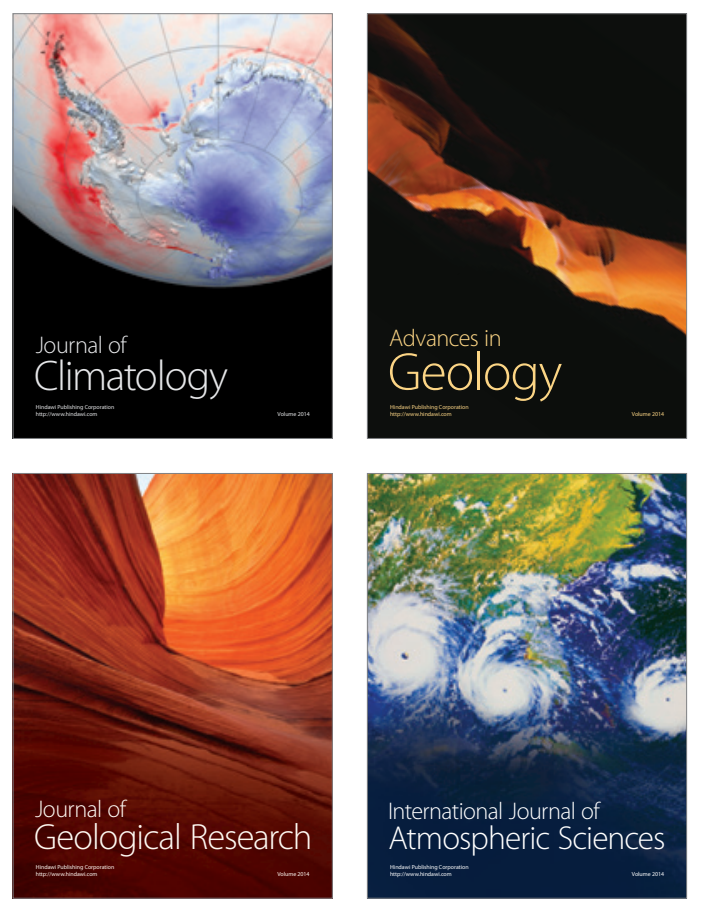

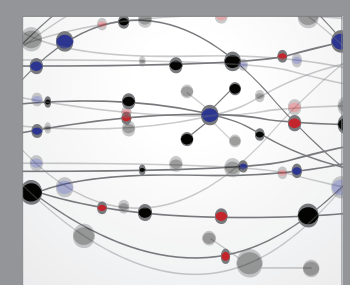

The Scientific

\section{World Journal}
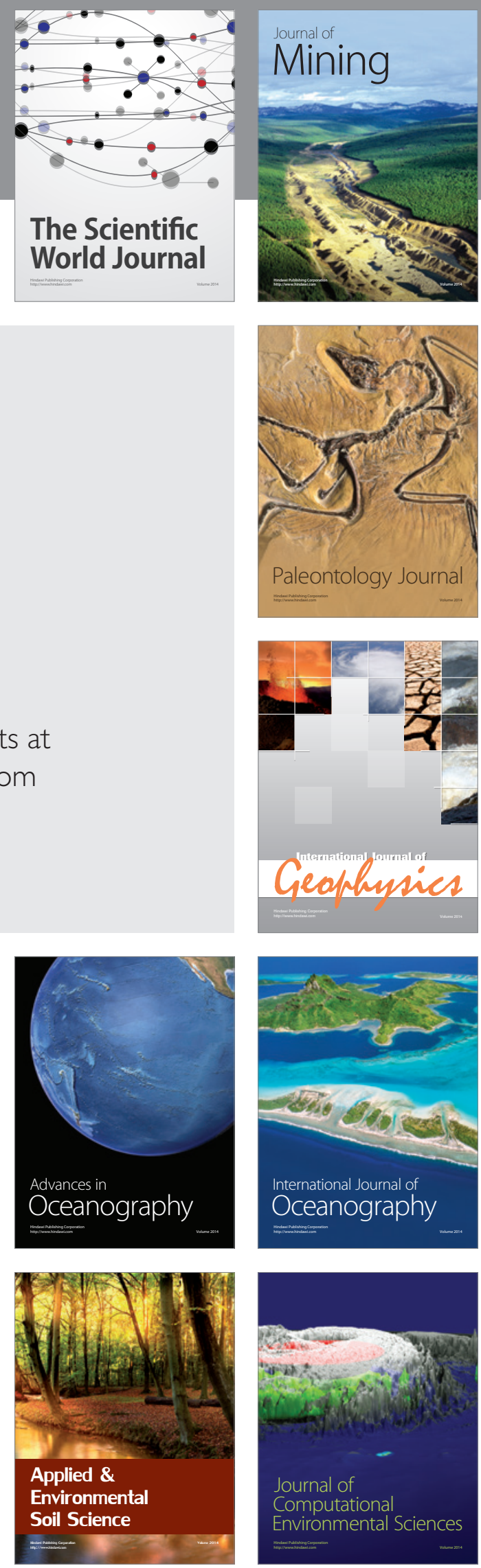